\title{
Carlos Fuentes en tres tiempos (1928-2012)
}

\author{
Carlos Fuentes \\ in Three Times (1928-2012)
}

\author{
Juan Gustavo Cobo Borda (Colombia) \\ coboborda@gmail.com \\ Institución Universitaria Politécnico Grancolombiano
}

\section{Resumen}

Juan Gustavo Cobo Borda presenta un análisis de las obras del escritor mexicano Carlos Fuentes. Haciendo un recorrido por su trabajo y los momentos más relevantes de su vida, Cobo admira e indaga sobre las motivaciones y pensamientos de este reconocido literato.

Palabras clave: literatura mexicana, Carlos Fuentes, literatura latinoamericana, México.

\begin{abstract}
Juan Gustavo Cobo Borda presents an analysis of the works of Mexican writer Carlos Fuentes. He takes a tour along his work and some of the most relevant moments in his life contemplating and researching on the motivation and thoughts of this well-known novelist.
\end{abstract}

Keywords: mexican literature, Carlos

Fuentes, latin american literature, Mexico.

\section{FECHA DE RECEPCIÓN: FECHA DE REVIIIÓN: APROBACIÓN:}

Para citar este artículo / to Cite this article

Cobo Borda, J. Carlos Fuentes en tres tiempos (1928-

2012). Poliantea, 8(15), 201-214. 


\title{
Carlos Fuentes en tres tiempos (1928-2012)
}

\begin{abstract}
Juan Gustavo Cobo Borda (Colombia)
Poeta y ensayista bogotano. Fue director durante una década (1973-1984) de la revista Eco, de la librería Buchholz, y Gaceta, del Instituto Colombiano de Cultura. Ha ocupado cargos diplomáticos en Buenos Aires y Madrid y fue embajador en Grecia. Miembro número de la Academia Colombiana de la Lengua desde 1993, y correspondiente, de la Academia Española. Ha sido jurado tres veces del Premio Juan Rulfo, (Guadalajara, México); del Rómulo Gallegos, (Caracas); del Reina Sofía de poesía iberoamericana (Madrid) y del Neustad, Universidad de Oklahoma, Estados Unidos. Ha colaborado con otras publicaciones, como Plural, de México, ABC, de España, y El Nacional de Venezuela. Entre sus poemarios figuran Consejos para sobrevivir (1974); Todos los poetas son santos (1987); Dibujos hechos al azar de lugares que cruzaron mis ojos (1991) y La musa inclemente (2001), entre otros. Algunas de sus publicaciones son Lengua Erótica: antología poética para hacer el amor (Villegas Editores, 2004), Lector impenitente, El olvidado arte de leer, Enclave de palabras número tres Acosado animal (Politécnico GrancoIombiano, 2010), Vargas Llosa: La pasión de narrar (Alfaguara, 2010), sus más recientes publicaciones.
\end{abstract}

I

Carlos Fuentes vivió, escribió y murió en "la ciudad más vieja del Nuevo Mundo". Una ciudad que desde 1325 ha estado siempre habitada y recreada. Una ciudad letrada, de capas superpuestas, que fue azteca, virreinal, neoclásica, moderna y sigue siendo todas ellas a la vez: México D. F.

Si en 1958 en La región más transparente efectúa el censo de la urbe, en gestos, voces y caracteres, también realiza un balance de la revolución traicionada y vendida al mejor postor de la aparente modernización. Lo popular de los caudillos arrasó con el porfiriato. Pero los negocios del capitalismo solo concedieron triunfar a los más astutos y venales de aquellos hombres a caballo.

Tal es el caso del coronel Artemio Cruz, cuya muerte es la tumba de ese viejo ideal que conmocionó al país: La muerte de Artemio Cruz (1962). A los setenta y un años, convertido en potentado, dueño de periódico, inversiones en bienes raíces, hombre de paja para cumplir con la ley en empresas mixtas mexicano-norteamericanas y quince millones de dólares en bancos de Zúrich, Londres y Nueva York. 
Pero detrás de estas dos primeras novelas siguen existiendo realidades subterráneas y determinantes. El Palacio Nacional, la antigua casa de Hernán Cortés, al igual que la catedral de México, están edificados con la piedra de Tenochtitlán, en superposición de cuatro siglos, donde la sangre del sacrificio humano se une a la imposición, cruz y espada, de lengua castellana y religión católica. La pirámide subsiste, posmodernizada. Pero el Templo Mayor puede resurgir del subsuelo como un lento terremoto, y cuartear la cuadrícula de la urbanización y el peso, tantas veces oneroso, de las demasiadas y puntillosas leyes.

Hay una vitalidad que se creía extirpada y que renace, águila y serpiente, agua quemada, con sus dioses que cobran venganza, que vuelven en los largos ciclos de Venus, en la vitalidad inexhausta de una riquísima cultura poopular. A 2.400 metros de altura se da este teatro de metamorfosis sin tregua que en Aura (1962) encuentra una fascinante y pionera confirmación.

La tía es la sobrina y Felipe Montero, el historiador, es el general Llorente sobre cuyos viejos papeles trabaja para darles forma a sus recuerdos. Aura es entonces el sueño del deseo que intenta volver a traer una forma apetecible, una niña-bruja que juega sexual y malignamente con gatos y que es simultánea y a la vez la señora Consuelo y Aura joven, "ojos de mar que fluyen, se hacen espuma, vuelven a la calma verde, se inflaman como una ola", tal como el general Llorente enamorado la describe.

La decrépita y desdentada es la que seduce, absorbe la sangre joven, trae al mundo su otro yo, esa Aura que desvelará y quizás enloquecerá, alucinado, al prometedor becario de la Sorbona que sueña con escribir un libro sobre el descubrimiento de América.

Pero que ahora, cautivo por la paga, en una casa también enclaustrada de la calle Donceles 815, cómo, en ese presente de la novela, la señora Consuelo tendrá hoy ciento nueve años y como viuda del general Llorente traerá a la luz otro trozo de la historia de México.

Los cuatro años, de 1863 a 1867, en que el archiduque Maximiliano de Austria reinará sobre México. Porque el general Llorente, quien fuera parte del círculo íntimo de Napoleón III, vendría con Maximiliano a México, hasta su fusilamiento. Enigma tras enigma, laberinto en pos de otro laberinto, como lo aclara Fuentes: 
"Aura y Consuelo son una persona, son ellas quienes sacan el secreto del deseo del corazón de Felipe. El varón queda engañado". (Obras reunidas, 2008, t. III, edición de Julio Ortega, p. 53).

El joven historiador, entre conejos y ratas, comidas donde siempre sirven riñones, y rituales, entre religiosos y satánicos, besará, acariciará y poseerá a Aura y estrechará en verdad un manojo de huesos frágiles: Consuelo, la vieja, atado de años que ya solo tiene fuerzas para traer por apenas tres días a su otro yo, seductor y apetecible. Pero el historiador atrapado eres tú, el lector. Esa segunda persona que se dirige a ti. Porque Montero es también Llorente en viejas fotografías. Aquel pelo blanco es tu actual barba negra. "Volverá, Felipe, la traeremos juntos. Deja que recupere fuerzas y la haré regresar"(Aura, 1967, p. 60). El pasado determinará toda la obra de Fuentes, en perpetuo impulso para escapar del tiempo y la muerte. De la inercia de los años ya caducados.

\section{Nota}

Entre 2007 y 2012, en cuatro amplios volúmenes, el Fondo de Cultura Económica de México ha publicado las Obras reunidas de Carlos Fuentes a cargo de Julio Ortega, con valiosas introducciones a cada una de sus novelas por firmas, como Segio Ramírez, Juan Goytisolo, José Emilio Pacheco, Carlos Monsiváis y Margo Glantz, entre otros. Las referencias corresponden a esta edición, donde las novelas se publican unidas por afinidades temáticas.

\section{II}

Como hijo de diplomático, Carlos Fuentes era cosmopolita, mundano y hablaba un perfecto inglés. Su iniciación sexual se dio en Buenos Aires, con una vecina refinada, y recordaría los cines de la calle Lavalle y las actrices emblemáticas de entonces, como Libertad Lamarque. También reflexionaría sobre Borges y Perón.

Pero este mexicano integral se casaría con una actriz de su país, Rita Macedo, y volvería autobiográfica ficción otra relación cinematográfica (con Jean Seberg). La novela se llamaría Diana o la cazadora solitaria (1994).

Pero estas pasiones por el séptimo arte no lo desviaban de su obsesiva vocación: la de narrar México, la de escribir con furia y exceso sobre cuerpos, países y conflictos. Mal contados, tengo aquí delante por 
lo menos cuarenta libros suyos en los que conviven cuento y novela, ensayo político y ensayo literario, obras de teatro y guiones en compañía, por ejemplo, de Gabriel García Márquez sobre textos de Juan Rulfo. Aproximaciones a la pintura (Viendo visiones), donde nos habla de Piero della Francesca, Velásquez y Fernando Botero, y panfletos virulentos como aquel contra George Bush. Sin olvidar la agilidad del periodista que cubrió en Praga, México y París las revueltas de 1968.

Era ambicioso y competitivo, pero era también de una generosidad inabarcable. Cuando en 1969 Fuentes publica La nueva novela latinoamericana, Borges y Carpentier, Vargas Llosa y Cortázar aparecen juntos por primera vez, relacionados con brillante ingenio.

En su último libro, titulado $\mathrm{La}$ gran novela latinoamericana (Alfaguara, 2011), los que vinieron cronológicamente después de él reciben una lectura comprensiva y profunda, trátese de Nélida Piñón o Sergio Ramírez, trátese de Jorge Volpi o Juan Gabriel Vásquez. Al final del libro este párrafo resulta revelador:

Cuando yo nací, en 1928, la Ciudad de México no llegaba al millón de habitantes. Cuando publiqué mi primera novela, La región más transparente, en 1958, había llegado a los cinco millones. Cuando Juan Villoro publicó El testigo, en 2005, el número de citadinos había rebasado los veinte millones. Digo esto porque, en cierto modo, yo contaba con una Ciudad de México más ceñida, abarcable en sus extremos, aunque nunca en sus honduras.

\section{El primer principio}

La región más transparente (título, tomado de una cita de Alfonso Reyes en su Visión de Anáhuac) hace alusión a la deslumbrada mirada con que los conquistadores españoles encontraron una civilización como la azteca, tan rica y compleja como las que ellos habían dejado al otro lado del mar. Con sus guerreros y sus poetas, sus astrónomos y sus emperadores, con sus pirámides para los sacrificios humanos y sus riquísimos mercados para alimentar muchos pueblos y muchas razas sometidas a su dominio. Todo ello lo vio bien Octavio Paz cuando escribió:

El centro secreto de la novela es un personaje ambiguo, Ixca Cienfuegos; aunque no participa en la acción, de alguna manera la precipita y es algo casi como la conciencia de la ciudad. Es la otra mitad de México, el pasado enterrado pero vivo. También es una máscara de Fuentes, del mismo modo que México es una máscara de Ixca. 
A partir de las reflexiones de Octavio Paz en El laberinto de la soledad (1950), Fuentes se pregunta, novelísticamente, por su país y por sí mismo. Y el hecho determinante, además de ese pasado indígena tan presente, que vio en la figura de Hernán Cortés el cumplimiento de un ciclo ya profetizado, es la Revolución mexicana. El fin de la dictadura de Porfirio Díaz y la transformación integral de un pueblo, en la lucha por el poder y la tierra, dividiéndose y asesinándose entre facciones burguesas y facciones populares, para ocupar el sillón presidencial, La silla del águila (2003), a la cual dedicaría toda una novela.

Pero si ahora el aire del valle de México se halla contaminado y los ideales han dado paso a los negocios, Fuentes busca, de 1946 a 1952, cuando transcurre la novela, durante la presidencia de Miguel Alemán, esclarecer la petrificación de un movimiento, pionero en el mundo, encaminado a reivindicar un campesinado y unos indígenas marginados en la periferia de ese núcleo plagado de tensiones, desde donde se distribuyen contratos y prebendas, tierras baldías y negocios acordes con la inserción de México en el mundo contemporáneo.
Vasto friso, donde los logros de la narrativa estadounidense (casos de Dos Passos y Faulkner) no desdeñan la herencia europea, que Fuentes conoce bien en figuras, como Balzac y Stendhal: la ambiciosa energía para usurpar un mundo. Acertó José Miguel Oviedo al describirla como novela sin argumento central,

[...] reemplazándolo por una serie de núcleos temáticos que se superponen o alternan. Estas características del diseño narrativo pueden producir cierta incoherencia o confusión, pero la novela impresiona por su empeño totalizador, su arrebato pasional, su humor a veces macabro y la riqueza desorbitada de sus imágenes, que tienen esa gestualidad barroquizante a la que Fuentes pronto nos acostumbraría. (Historia de la literatura hispanoamericana. Tomo 4. De Borges al presente. Madrid: Alianza Editorial, 2001, p. 318).

Desde el exrevolucionario convertido ahora en banquero, Federico Robles, quien dice con fresco cinismo: "La militancia ha de ser breve y la fortuna larga", hasta el bracero que trabajó en Estados Unidos y muere en forma violenta, todo el espectro social es recorrido por la mirada incisiva y crítica de Fuentes, quien también se mira a sí mismo en personajes, como el 
intelectual que indaga sobre la ontología del ser mexicano y el poeta frustrado que termina en guionista de banalidades.

El fracaso de la revolución para un orden más justo es también el fracaso de las personas que ven cómo su destino se elude en la inautenticidad. Por ello, cuando Fuentes en un disco leyó fragmentos de la novela, logró recrear la música y la letra de los diversos personajes, y el riquísimo repertorio que va desde los corridos de la revolución a la poesía que alimenta el fuego de esta novela impura y polifacética. Reflexiva y corporal. Alimentada por el venero de la tragedia, pero también exorcizada en el carnaval promiscuo de la risa y la comedia: "Tuna incandescente. Águila sin alas. Serpiente de estrellas. Aquí nos tocó. Qué le vamos a hacer. En la región más transparente del aire". (La región más transparente, Real Academia Española-Alfaguara, 2008, p. 21)

\section{Los otros principios}

Quizás uno de los ejes más llamativos de la obra de Fuentes es su capacidad de romper la cortina de nopal de su país, como la denominó el pintor José Luis Cuevas, y dialogar de tú a tú con el mundo y con la historia.
En tal sentido, Terra nostra (1975) y El espejo enterrado (1992) forman un díptico de novela-ensayo en torno a España, su relación consigo misma y su incidencia en los países conquistados. En su dedicatoria, Fuentes escribió: “Terra Nostra es para Juan Gustavo, con una pléyade de monarcas, bufones, enanos, sacerdotes, conquistadores y demás ciudadanos de la primera globalidad: la hispánica”.

Fuentes sabía muy bien, entre la Inquisición y los herejes, que el primer imperio mundial era el español de Felipe II y cómo por su desmesura estaba condenado a fracasar. Un hombre solo, en un jardín monástico, no podía abarcar el globo terráqueo de Madrid a Filipinas, de Nápoles a los Países Bajos. Pero todos los memoriales eran minuciosamente revisados (que si un puesto en las Indias para Miguel de Cervantes) en una morosa cadena burocrática que el rey inauguraba e iba naufragando poco a poco en las aguas letales del archivo, los sellos y las recomendaciones. Con razón, como cuenta Fuentes en El espejo enterrado: "Un proverbio corriente en Europa en aquel tiempo expresaba el deseo de que nuestra muerte nos llegase de España, pues en este caso llegaría tarde a la cita". ( $E l$ 
espejo enterrado, México, Fondo de Cultura Económica, 1992, p. 177).

El hombre que comprendió a México, reflexionó sobre España y en el momento inicial del boom literario dio testimonio de su fraterno apoyo a sus amigos, como Mario Vargas Llosa, era también un creador al que le fascinaba la exploración de los vericuetos secretos y de las posesiones diabólicas, como son dos de sus libros sobre el lado oscuro de los seres: Aura y Vlad, sin olvidar que muchas de sus novelas están tejidas sobre partituras musicales.

Pero el hombre que unido a la periodista Silvia Lemus, durante tantos años, mantuvo la actitud crítica ante todos los fenómenos políticos de América y del mundo es también el conmovido padre que recuerda las fotos de su hijo fallecido en el libro Retratos en el tiempo (1998), en el cual aparecen figuras, como Milan Kundera, Norman Mailer, Arthur Miller, Susan Sontag, William Styron y García Márquez, y que corrobora la capacidad de diálogo y de controversia fecunda que Carlos Fuentes supo irradiar durante toda su vida.

\section{III}

Personas (2012), el primer libro póstumo de Carlos Fuentes, es muchas cosas a la vez. Una galería de retratos: Alfonso Reyes y Luis Buñuel, François Mitterrand y André Malraux, Pablo Neruda y Julio Cortázar, Arthur Miller y Lázaro Cárdenas. Suerte de memorias indirectas sobre maestros que lo marcaron como estudiante de Derecho, en México, como el exiliado español Manuel Pedrero que en sus cursos sobre Teoría del Estado y Derecho Internacional Público limitaba las lecturas a solo tres autores: Platón, Maquiavelo y Rousseau. Platón, en el cual la paideia, ideal de cultura como principio formativo del individuo, con un amplio devenir histórico, ya que el tiempo no es más que la eternidad en movimiento.

Más tarde hallará otros guías, como el economista canadiense John Kenneth Galbraith, el autor de El nuevo Estado industrial que abrirá para Fuentes "el teatro del mundo económico" actual y su incidencia en nuestros países:

Ninguna compañía privada que se respete a sí misma, comentó Galbraith, se abandonaría a los vaivenes del mercado. Verdad central para fortalecer a los Estados latinoamericanos, $\tan$ incipientes 
aún, sin menospreciar a la iniciativa privada y apelando a la sociedad civil. Quienes reclaman que el Estado se ausente, no podrían sostener, sin el Estado, los territorios que reclaman, trátese de la defensa nacional, de la solidaridad social o de la regulación de la banca privada. (Personas, 2012, p. 73).

Otros perfiles, de gran vivacidad emotiva, son aquellos que dedica a amigos muy próximos, verdaderos “cuates", como Fernando Benitez con quien practicó Fuentes un periodismo independiente y crítico, como en el suplemento La cultura en México donde documentaron "el asesinato del líder agrario Rubén Jaramillo y su familia al pie de la pirámide de Xochicalco" (p. 114). Un excelente reportaje que puede encontrarse en su recopilación Tiempo mexicano (1971, pp. 109-122).

La trashumancia cosmopolita de Carlos Fuentes, siempre cerca de los acontecimientos y los grandes personajes, siempre obsesiva sobre México y su pasado indígena, siempre en lucha por un espacio democrático más allá del Partido Revolucionario Institucional (PRI), tiene un aliciente de avidez creativa: su ambición de novelista. El vasto ciclo de su narrativa que él mismo denominó La edad del tiempo y que en la solapa de este libro abarca 25 títulos por lo menos y varios otros que fueron apenas intentos o borradores que no cuajaron, como su proyecto sobre uno de los líderes del Movimiento 19 de Abril (M-19), Carlos Pizarro, que tituló Aquiles o el guerrillero y el asesino.

Darle al pasado inerte un presente vivo, prestarle voz actual a los silencios de la historia [...] si no salvábamos nuestro pasado para hacerlo vivir en el presente, no tendríamos futuro alguno (Personas, 2012, p. 142).

Este era, en cierto modo, el decálogo del Fuentes novelista y su generosa preocupación por el destino de la novela a través del estudio y el reconocimiento de sus pares, como es el caso de su muy ilustrativo libro Geografía de la novela (1993), armado en torno a figuras, como Roa Bastos, Milan Kundera, Julian Barnes, Italo Calvino y Salman Rushdie, y que ahora, en Personas, se prolonga en su retrato de Susan Sontag.

Allí donde la frialdad taxonómica de los profesores se vuelve el dinámico testimonio de un participante comprometido que sentía cómo la realidad parecía sobrepasarlo. Su México de 110 millones de personas y 50.000 asesinatos terminaba por resultar inabarcable en las 
disputas entre los carteles de la droga y el retorno del PRI al poder. Paradojas de la historia que Fuentes asumía en la ironía de aquel "jamás real, siempre verdadero" con que la novela, a través de la imaginación y el lenguaje, crea los mundos que nos faltan, donde la experiencia se vuelve conocimiento y la libertad surge, una vez más, de la necesidad. "En literatura, nos confirmó Borges, la realidad es lo imaginado". Todo ello, en contra quizás de esa tradición mexicana autoritaria e intolerante como buena hija de Moctezuma y Felipe II, que Fuentes cuestionó con pasión desde los primeros seis cuentos de su libro inicial Los días enmascarados (1954). La pétrea máscara del ídolo azteca que el Creador debe destruir para que surja el rostro humano. Por ello, a través de estas figuras bien comprendidas y dibujadas con acierto, como es el caso de Buñuel y Lázaro Cárdenas, el que termina por asomar es el propio Carlos Fuentes.

Un lector que, en filósofas como María Zambrano y Simone Weil, también encuentra fundamentos para sus análisis que, en este libro de lúcido memorialista, nos da otra vía para acercarnos a las personas que conformaron su educación cívica y creativa.
A partir de allí, podemos, por lo tanto, internarnos en algunas de las facetas de su incesante actividad.

\section{Referencias}

Cuentos y novelas

Los días enmascarados (1954) (seis cuentos), México, 2. ${ }^{a}$, Biblioteca Era, 1983. "Los días enmascarados es mi primer libro y J. G. Cobo Borda, mi primer lector -siempre", 1999.

La región más transparente (1958), México, Fondo de Cultura Económica, 6. ${ }^{a}$, reimpresión en Colección Popular, 1968.

Las buenas conciencias (1959), México, Fondo de Cultura Económica, 2. ${ }^{a}$, Colección Popular, 1959.

La muerte de Artemio Cruz (1962), México, Fondo de Cultura Económica, 2. ${ }^{a}$, Colección Popular, 1965. Aura (1962) México, Ediciones Era, 3. ${ }^{\mathrm{a}}, 1966$.

Cantar de ciegos (1964) (siete cuentos), México, Editorial Joaquín Mortiz, Joaquín Mortiz, 1966.

Zona sagrada (1967), México, Siglo XXI, 3. a 1967.

Cambio de piel (1967), México, Editorial Joaquín Mortiz, 1. a, 1967. “A 
Juan Gustavo Cobo Borda, esta edición tamizada por la censura franquista", 1999.

Cumpleaños (1969), México, Editorial Joaquín Mortiz, 1. a 1969.

Terra Nostra (1975), Barcelona, Seix Barral, 1. a , 1975. "Terra Nostra es para Juan Gustavo con una pléyade de monarcas, bufones, enanos, sacerdotes, conquistadores y demás ciudadanos de la primera globalidad: la Hispánica”, 1999.

La cabeza de la hidra (1978), Barcelona, Argos. Vergara, 1. ${ }^{\mathrm{a}}, 1978$.

Una familia lejana (1980), México, Ediciones Era, 1. ${ }^{\text {a }} 1980$.

Agua quemada. Cuarteto narrativo (1981), México, Fondo de Cultura Económica, 2.a julio 1981.

Gringo viejo (1985), México, Fondo de Cultura Económica, $1 .^{\text {a }}$ reimpresión, 1985.

Cristóbal Nonato (1987), Madrid, Mondadori, 1992.

Constancia y otras novelas para vírgenes (1990), México, Fondo de Cultura Económica, 1. ${ }^{a}$ reimpresión, 1991.
La campaña (1990), México, Fondo de Cultura Económica, 1. ${ }^{\mathrm{a}}$ reimpresión, 1991.

El naranjo (1993), México, Alfaguara, 3. ${ }^{a}$ reimpresión, septiembre de 1993.

Diana o la cazadora solitaria (1994), México, Alfaguara, 1. a edición, mayo de 1994.

Los años con Laura Díaz (1999), México, Alfaguara, $1 .^{\mathrm{a}}$ reimpresión, 1999.

Instinto de Inez (2000), Madrid, Alfaguara, 2001.

La silla del Águila (2002), México, Alfaguara, 2. ${ }^{a}$ reimpresión, 2003.

Inquieta compañía (2003), México, Alfaguara, 1. ${ }^{\mathrm{a}}$ edición, 2004.

Todas las familias felices (2006), Bogotá, Alfaguara, 1. ${ }^{\mathrm{a}}$ reimpresión, 2007.

La voluntad y la fortuna (2008), Bogotá, Alfaguara, 1. ${ }^{a}$ edición, 2008.

Adán en Edén (2009), Bogotá, Alfaguara, 1 . $^{\mathrm{a}}$ edición en Colombia, febrero de 2010.

Carolina Grau (2010), México, Alfaguara, 1. ${ }^{a}$ edición, octubre de 2010. 
Federico en su balcón (2012), Bogotá, Alfaguara, 2012.

Obras reunidas, t. I-IV, México, Fondo de Cultura Económica, 2008.

\section{Nota aclaratoria}

La región más transparente tiene dos ediciones acompañadas por dosier crítico. La primera de Alfaguara, México, marzo de 1998, incluye textos de Luis Cardoza y Aragón, Salvador Novo, José Alvarado, Fernando Benítez, Miguel Ángel Asturias y Salvador Elizondo y cartas de Julio Cortázar y José Lezama Lima. La segunda es la edición conmemorativa de la Real Academia Española y la Asociación de Academias de la Lengua Española, impresa por Alfaguara, España, noviembre de 2008. Incluye trabajos de Gonzalo Celorio, José Emilio Pacheco, Vicente Quirarte, Carmen Iglesias, Sergio Ramírez, Nélida Piñón y Juan Luis Cebrián. También glosario y bibliografía. 